\title{
ก่ำ่ talentabijois
}

\section{THE CHARACTERISTICS OF NASOPHARYNGEAL CARCINOMA PATIENTS IN MOHAMMAD HOESIN GENERAL HOSPITAL PALEMBANG}

\author{
Denny Satria Utama ${ }^{I^{*}}$ Eriza $^{2}$,Ita Wahyuni ${ }^{3}$,Apriyanza Akbar ${ }^{1}$ \\ ${ }^{I}$ Department of Otorhinolaryngology Head and Neck Surgery, Faculty of Medicine Universitas Sriwijaya, RSUP Dr. Moehammad Hoesin Palembang \\ ${ }^{2}$ RSUD Mayjen HM. Ryacudu, Lampung Utara \\ ${ }^{3}$ RSUD Kayuagung, Kabupaten Ogan Komering Ilir
}

\begin{abstract}
Introduction: Nasopharyngeal carcinoma is a malignant tumor that grows in a nasopharyngeal area with a predilection in fossa of Rossenmuller and roof of the nasopharynx. Nasopharyngeal carcinoma is the most common malignant tumor in the neck and head area.

Objectives: to determine the characteristics of nasopharyngeal carcinoma at Mohammad Hoesin Genera Hospital Palembang.

Methods: This study design is retrospective descriptive and took the sample from medical records in Departmen of ORL-HNS Mohammad Hoesin General Hospital Palembang between January 2013 until December 2017. Results: In this study, the number of nasopharyngeal carcinoma patients from January 2013 to December 2017 was 284 patient. Most of them were male (72.86\%). The age of most patients ranges from 41-50 years $(33.20 \%)$. The highest histopathological description of patients was WHO 2B (54.9\%). Most patients were T4 (36.29\%). Most patients nodules were N3 (34.09\%). As many as $93.88 \%$ of patients have not experienced distant metastasis. Most patients came to the department of ORL-HNS had already been in stage IV (63.84\%). The most chemotherapy regimens given were carboplatin and docetaxel.

Conclusions: The patients of Nasopharyngeal Carcinoma in Mohammad Hoesin General Hospital Palembang are mostly male, middle-age adults and advanced stage. Nasopharyngeal carcinoma is still a problem in many countries. The main management is radiotherapy with or without chemotherapy.
\end{abstract}

\section{Article Info}

Keywords:

Nasopharyngeal Carcinoma, Characteristic, ORLHNS, Palembang

\section{*Corresponding author}

Address: Jalan. Rustini Perumahan Caldonia Residance Blok A7/8, Kecamatan Sako Kota, Kelurahan Suka Maju, Palembang 30164

e-mail: dennyutama77@gmail.com

\section{INTRODUCTION}

Nasopharyngeal carcinoma is still a problem in the health sector. In Indonesia, nasopharyngeal carcinoma occupies the fifth largest cancer and is the most malignant tumor in the head and neck, which is about $60 \%$, followed by malignant tumors of the nasal cavity and paranasal sinuses, malignant laryngeal tumors, malignant oral tumors, malignant tonsillar tumors, and hypopharyngeal malignant tumors. The location of the nasopharynx in a place that is relatively hidden and the symptoms that are caused are often not typical, making this tumor often late in diagnosis. Nasopharyngeal carcinoma is a malignant tumor characterized by changes in the nasopharyngeal mucosal epithelium especially in the fossa of Rosenmuller from the cuboid epithelium to the squamous epithelium. The diagnosis of nasopharyngeal carcinoma is established from history, physical examination, and investigation $[1,2]$.

The exact diagnosis of nasopharyngeal carcinoma by histopathological examination. The initial signs of nasopharyngeal carcinoma are often the enlarging lymph nodes of the neck. These early symptoms and signs are often uncharacteristic and neglected unless neurological symptoms have arisen which are typical signs of nasopharyngeal carcinoma. Clinical manifestations of nasopharyngeal carcinoma can be grouped into 4 categories, which are nasopharyngeal symptoms, symptoms of tubal dysfunction, symptoms of cranial base involvement, and symptoms of the neck mass. Anamnesis in patients with early-stage nasopharynx is usually found symptoms of the ear feels closed on one side, and the nose is constantly blocked. In advanced stages, epistaxis and enlarged lymph nodes in the neck area can be found [2-4].

From the physical examination, we can find an enlarged neck, supraclavicular lymph nodes. The investigation can be done with telenosendoscopy and nasopharyngeal mass originating from the fossa of Rossenmuller can be found. Computer Tomography (TK) and nasopharyngeal magnetic resonance imaging (MRI) to determine tumor expansion. Based on a report from the Global Burden Cancer (GLOBOCAN) in 2012, 87.000 new cases of nasopharyngeal carcinoma appeared every year (with 61.000 new cases in men and 26.000 new cases in women), 51.000 deaths from nasopharyngeal carcinoma (36.000 in men and 15.000 in women). According to that report based on age standardized rate (ASR), incidence of nasopharyngeal carcinoma in Indonesia was 8.3/100.000 in male, and $3.0 / 100.000$ in female. The highest incidence of patients with nasopharyngeal carcinoma in the world is in southern China, especially in Guangdong and Guangxi. Most sufferers of nasopharyngeal carcinoma are aged 40 to 50 years, although currently there are many nasopharyngeal carcinomas affecting children and adolescents. Nasopharyngeal carcinoma is more common in men, with a comparison of male and female nasopharyngeal carcinoma patients, 2-3:1 [2-4]

Management of nasopharyngeal carcinoma depends on the stage. The main modality for managing nasopharyngeal carcinoma is radiotherapy with or without chemotherapy. Nasopharyngeal carcinoma complications can be caused either by the tumor or by treatment of nasopharyngeal cancer. Complications of nasopharyngeal carcinoma include early complications and advanced complications. Early stage nasopharyngeal carcinoma has a better prognosis compared to advanced nasopharyngeal carcinoma. Nasopharyngeal carcinoma has a worse prognosis at an advanced stage, over 40 years of age, male gender [4-6].

The study aimed to determine the characteristics in the form of demographic data, stages, regimens used and therapeutic progress in patients with nasopharyngeal carcinoma at the Department of ORL-HNS Dr. Moehammad Hoesin Hospital Palembang. It is expected that this data can be used as basic data for further Study. 


\section{MATERIAL AND METHODS}

This Study was a retrospective descriptive study. The data was taken from the medical records of patients with nasopharyngeal carcinoma at the Department of ORL-HNS Dr. Moehammad Hoesin Hospital Palembang. This study was conducted in January 2013 until December 2017. The place of Study was conducted at the Department of ORL-HNS Dr. Moehammad Hoesin Hospital Palembang. Sampling by total sampling with the criteria of all nasopharyngeal carcinoma patients from January 2013 to December 2017. This study described the patient demographic data including age, gender, histopathological description, tumor location based on computer tomography, enlarged lymph node nodules, further metastasis, patient tumor stage. In addition, this study also describes the chemotherapy regimen used in the treatment of nasopharyngeal carcinoma and the current state of the patient. After the chemotherapy, the patients was treated with radiotherapy. The results of the study are presented descriptively in the form of narratives and tables.

\section{RESULT}

Based on medical record data from Department of ORL-HNS Dr. Moehammad Hoesin Hospital Palembang, there were 284 patient with nasopharyngeal carcinoma from January 2013 to December 2017.

Table 1. The characteristics of nasopharyngeal carcinoma based on gender

\begin{tabular}{|c|c|c|}
\hline Gender & $\mathrm{n}$ & $\%$ \\
\hline $\begin{array}{l}\text { Male } \\
\text { Female } \\
\end{array}$ & $\begin{array}{r}207 \\
77 \\
\end{array}$ & $\begin{array}{l}72.88 \\
27.12 \\
\end{array}$ \\
\hline Total & 284 & 100 \\
\hline
\end{tabular}

In this study, of 284 patients, there were 207 male $(72.88 \%)$ and 77 women $(27.12 \%)$. Distribution of nasopharyngeal carcinoma patients by gender can be seen in table 1 .

Table 2. The characteristic of nasopharyngeal carcinoma patients based on age

\begin{tabular}{|c|c|c|}
\hline Age (year) & n & $\%$ \\
\hline $11-20$ & 12 & 4.30 \\
\hline 21-30 & 30 & 10.60 \\
\hline $31-40$ & 65 & 22.66 \\
\hline $41-50$ & 95 & 33.20 \\
\hline $51-60$ & 50 & 17.80 \\
\hline$\geq 61$ & 32 & 11.44 \\
\hline Total & 284 & 100 \\
\hline
\end{tabular}

In this case Study, the majority of the nasopharyngeal carcinoma patients were $41-50$ years old with 95 patient $(33.20 \%)$. The next most patient age group is $31-40$ years as many as 65 patient (22.66\%), age groups $51-60$ years as many as 50 patients $(17.8 \%)$, age groups equal to or above 61 years as many as 32 patient $(11.44 \%)$. While the age group of $21-30$ years is 30 patient $(10.6 \%)$, and the age group of $11-20$ years is 12 patient $(4.3 \%)$. The distribution of nasopharyngeal carcinoma patients by age group can be seen in table 2 .

Table 3. The characteristic of nasopharyngeal carcinoma patients based on histopathology

\begin{tabular}{lrr}
\hline \multicolumn{1}{c}{ Histopathology } & $\mathbf{n}$ & $\%$ \\
\hline WHO 1 & 8 & 2,8 \\
WHO 2A & 63 & 22,2 \\
WHO 2B & 156 & 54,9 \\
WHO 3 & 57 & 20,1 \\
\hline Total & $\mathbf{2 8 4}$ & $\mathbf{1 0 0}$ \\
\hline
\end{tabular}

Based on histopathology, most nasopharyngeal carcinoma patients is WHO 2B nasopharyngeal carcinoma of 156 patient (54.9\%). Furthermore, the most histopathological picture of nasopharyngeal carcinoma is $\mathrm{WHO} 2 \mathrm{~A}$ as many as 63 patient $(22.2 \%)$ followed by WHO 3 as many as 57 patients $(20.1 \%)$ and WHO 1 as many as 8 patients (2.8\%). Distribution of nasopharyngeal carcinoma patients based on histopathology can be seen in table 3 .

Table 4. The characteristic of nasopharyngeal carcinoma patients based on tumor

\begin{tabular}{|c|c|c|}
\hline Tumor & $\mathbf{n}$ & $\%$ \\
\hline $\mathrm{T} 1$ & 19 & 6.73 \\
\hline $\mathrm{T} 2$ & 66 & 23.17 \\
\hline T3 & 96 & 33.81 \\
\hline $\mathrm{T} 4$ & 103 & 36.29 \\
\hline Total & 284 & 100 \\
\hline
\end{tabular}

From the image of computed tomography, the location of the tumor was the highest number of T4 tumors as many as 103 patient $(36.29 \%)$, then the T3 tumor image with 96 patient (33.81\%), the next most tumor image is T2 of 66 patient $(23.17 \%)$, and the most recent is $\mathrm{T} 1$ images of 19 patient $(6.73 \%)$. Distribution of tumor images based on computer tomography can be seen in table 4 .

Table 5. The characteristic of nasopharyngeal carcinoma patients based on nodule

\begin{tabular}{lcc}
\hline \multicolumn{1}{c}{ Nodule } & $\mathbf{n}$ & $\boldsymbol{\%}$ \\
\hline N0 & 36 & 12.68 \\
N1 & 56 & 19.76 \\
N2 & 95 & 33.47 \\
N3 & 97 & 34.09 \\
\hline Total & $\mathbf{2 8 4}$ & $\mathbf{1 0 0}$ \\
\hline
\end{tabular}

Based on the description of neck lymph node metastasis, in this Study the most nodules were obtained is N3 nodules as many as 97 patient $(34.09 \%)$. Furthermore, the second most N2 nodules are 95 patient $(33.47 \%)$, N1 nodules as many as 56 patient $(19.76 \%)$, and N0 as many as 36 patient (12.68\%). Distribution of nasopharyngeal carcinoma patients based on neck lymph node nodules can be seen in table 5 .

Table 6. The characteristic of nasopharyngeal carcinoma patients based on Stage

\begin{tabular}{|c|c|c|}
\hline Stage & n & $\%$ \\
\hline I & 12 & 4.31 \\
\hline II & 37 & 13.19 \\
\hline III & 54 & 18.66 \\
\hline IV & 181 & 63.84 \\
\hline Total & 284 & 100 \\
\hline
\end{tabular}

In this study, the majority of nasopharyngeal carcinoma patients are stage IV nasopharyngeal carcinoma of 181 patient (63.84\%). Patients with stage III nasopharyngeal carcinoma are 54 patient (18.66\%), stage II nasopharyngeal carcinoma are 37 patient $(13.19 \%)$ and stage I nasopharyngeal carcinoma are 12 patient $(4.31 \%)$. Distribution of nasopharyngeal carcinoma patients based on their stage can be seen in table 6 .

Table 7. The characteristic of nasopharyngeal carcinoma patients based on metastasis

\begin{tabular}{lcc}
\hline \multicolumn{1}{c}{ Metastasis } & $\mathbf{n}$ & $\%$ \\
\hline M0 & 267 & 93.88 \\
M1 & 17 & 6.12 \\
\hline Total & $\mathbf{2 8 4}$ & $\mathbf{1 0 0}$ \\
\hline
\end{tabular}

Based on the description of further metastasis, of 284 nasopharyngeal carcinoma patients, 267 patient $(93.88 \%)$ had no further metastases and as many as 17 patients $(6.12 \%)$ had further metastases. Distribution of nasopharyngeal carcinoma patients based on the description of further metastases can be seen in table 7 .

Table 8. The characteristic of nasopharyngeal carcinoma patients based on chemotherapy regimen

\begin{tabular}{lrc}
\hline \multicolumn{1}{c}{ Regimen } & n & $\%$ \\
\hline Carboplatin + & 182 & 64.0 \\
$\begin{array}{l}\text { Docetaxel } \\
\text { Cetuximab + }\end{array}$ & 86 & 30.2 \\
Carboplatin+Docetaxel & 10 & 3.5 \\
Refused Chemotherapy & 6 & 2.3 \\
$\begin{array}{l}\text { Haven't time to get } \\
\text { Chemotherapy }\end{array}$ & $\mathbf{2 8 4}$ & $\mathbf{1 0 0}$ \\
\hline Total &
\end{tabular}

Based on the chemotherapy regimen obtained by nasopharyngeal carcinoma patients, 182 patient $(64 \%)$ received a carboplatin and docetaxel combination regimen. A total of 86 patient $(30.2 \%)$ received a combination regimen of cetuximab, carboplatin, and docetaxel. 10 patient (3.5\%) refused chemotherapy, and 6 patient $(2.3 \%)$ did not have time to get chemotherapy because they died (Table 8 ).

Table 9. The characteristic of nasopharyngeal carcinoma patients based on response to therapy and the current situation

\begin{tabular}{lrr}
\hline \multicolumn{1}{c}{ Condition } & n & \% \\
\hline Died & 79 & 27.91 \\
Complete response & 11 & 3.89 \\
Respond to therapy & 116 & 40.71 \\
No response & 32 & 11.27 \\
Didn't control & 46 & 16.22 \\
\hline Total & $\mathbf{2 8 4}$ & $\mathbf{1 0 0}$ \\
\hline
\end{tabular}


Based on the response and condition of the patient to therapy, nasopharyngeal carcinoma patients currently died as many as 79 patient (27.91\%). A total of 11 patient (3.89\%) complete responses and became stadium TONOM0, as many as 116 patient (40.71\%) experienced progress in therapy, 32 patient $(11.27 \%)$ did not respond to therapy and 46 patient $(16.22 \%)$ did not control anymore. Distribution of nasopharyngeal carcinoma patients based on the response to therapy and the current situation can be seen in table 9 .

\section{DISCUSSION}

Nasopharyngeal carcinoma is still a common problem in developing countries. In the world, there are 65,000 new cases every year. In this study, there was 284 patient suffering from nasopharyngeal carcinoma from 2013 to 2017 . The prevalence of nasopharyngeal carcinoma is more than $80 \%$ in southern China and south east Asia. In the UK the incidence of nasopharyngeal carcinoma is found in 0.5 of 100,000 inhabitants, and about $1-2 \%$ of all malignancies in the head region. Whereas in America there were 2000 new cases per year. In Indonesia, nasopharyngeal carcinoma ranks first in head and neck cancer. The prevalence continues to increase, presumably due to increased consumption of preservative foods and poor socio-economic conditions $[1,2,4]$.

In this study, it was found that nasopharyngeal carcinoma was more common in men than women in a ratio of $3: 1$. According to a study conducted by Adham $\mathrm{M}$ et al., it was mentioned that the incidence of nasopharyngeal carcinoma was more prevalent among men than women with a ratio of $2-3: 1$. This explains that nasopharyngeal carcinoma is influenced by gender. This may be due to several factors causing nasopharyngeal carcinoma often found in men, such as smoking, drinking alcohol, and exposure to wood dust [7].

In this study, it was found that the majority of nasopharyngeal carcinoma patients in the 41-50 year age group with 95 patient. According to Study by Yurnadi et al., It was mentioned that nasopharyngeal carcinoma is more prevalent between the ages of 40-50 years, this may be explained by the pathogenesis of the occurrence of nasopharyngeal carcinoma due to chronic processes. Normal cells transform into cancer cells due to spontaneous mutations or carcinogen induction. Allegedly the main cause of nasopharyngeal carcinoma is the consumption of preservative foods containing nitrosamines such as salted fish, and fish that are preserved by fumigation. Besides, environmental factors such as dirty and stuffy air and slum environments are also thought to play a role in the incidence of nasopharyngeal carcinoma $[8,9]$.

In this study, the most histopathological description of nasopharyngeal carcinoma was WHO 2B type of 156 patient. The Study conducted by Yenita et al. in West Sumatra, found that the most histopathological picture of nasopharyngeal carcinoma was WHO 2B. From this study, it was found that the WHO 2B picture contained 156 patient or $54.9 \%$, WHO $2 \mathrm{~A}$ as many as 63 patient $(22.2 \%)$, and WHO 1 as many as 8 patients $(2.8 \%)$. The WHO $2 \mathrm{~B}$ picture has a better prognosis [10].

In this study, the highest number of computer tomography of patients was T4 with 103 patient, T3 was 96 patient, T2 was 66 patient, and T1 was 19 patient. Hidden nasopharyngeal location and sometimes unusual symptoms often make patients come in a large tumor state. From the picture of the neck lymph node nodules, it was found that most patients with N3 lymph node enlargement as many as 97 patient, N2 as many as 95 patient, N1 as many as 56 patient, and N0 as many as 36 patient. Neck lymph glands that are felt to be painless often cause patients to ignore complaints from the neck. In addition, enlarged lumps slowly also often make the patient ignore the symptoms of a lump on his neck so that patients come already in an advanced stage [11].

In this study there were 103 patients with stage IV, 96 patient with stage III, 66 patient coming with stage II, and 19 patient coming in with stage I. In a study conducted by $\mathrm{Li}$ et al., 42 patients arrived at an advanced stage, $25 \%$. Another study conducted by Adelien at Dr. Moehammad Hoesin Hospital Palembang said that as many as $84.1 \%$ of patients came at an advanced stage (stage III and IV). Factors in the patient's ignorance, Location of the nasopharynx is hidden, symptoms that are not typical of nasopharyngeal carcinoma often make the patient come in an advanced stage. In addition, symptoms of neck lumps that are felt to be painless often make the patient ignore the disease $[12,13]$.

In this study, a description of further metastasis was obtained, with 17 patients with further metastases and 267 patient not metastasizing. Further metastasis is rarely found in nasopharyngeal carcinoma patients. As $\mathrm{Li}$ et al. Report, further liver metastases were found in 1 patient, lung metastases were 3 patient from 351 patients in their study [14].
The most chemotherapy regimen used for the treatment of nasopharyngeal carcinoma in this study was a combination of carboplatin and docetaxel regimens, 182 patient. While the combined cetuximab, carboplatin and docetaxel regimens were 86 patient, and 10 patient refused chemotherapy, and 6 patient didn't have chemotherapy. Carboplatin is an analog of cisplatin. This drug was developed because of the toxic effects of cisplatin on the kidneys and nerve fibers. Carboplatin causes lighter side effects of nausea, neurotoxicity, ototoxicity, and nephrotoxicity than cisplatin, but more effects of myelosuppression appear especially thrombocytopenia. Cetuximab is used as a targeted therapy. Cetuximab is used in initial therapy at locoregional advanced stage nasopharyngeal carcinoma. In this study, the patients was treated with radiotherapy after chemotherapy. [14,15].

\section{CONCLUSION}

Nasopharyngeal carcinoma is still a problem in many countries, especially in developing countries. Although the exact cause of nasopharyngeal carcinoma is not known with certainty, it is suspected that many factors trigger this cancer. The trigger factors for nasopharyngeal carcinoma include genetic, environmental factors, and Epstein-Barr virus infection. In this study, the patients of nasopharyngeal carcinoma are mostly male, middle-age adults and advanced stage. Nasopharyngeal carcinoma patients often come in an advanced stage, because several factors include the patient's ignorance of the disease, the hidden nasopharynx, making it difficult to diagnose, and the nasopharyngeal symptoms that are caused are often not typical. Management mainly with radiotherapy with or without chemotherapy. Further metastasis is rarely found in nasopharyngeal carcinoma patients, that worsen the prognosis of nasopharyngeal carcinoma are age above 40 years, male gender, and the presence of further metastases.

\section{REFERENCE}

[1] Roezin A, Adham M. Karsinoma Nasofaring, dalam Buku Ajar THT commit to user FKUI. Jakarta, hal; 2007.

[2] Wei W, Chua D. Nasopharyngal cancer. Dalam Bailey BJ, Healey GB, Johnson JT, Rosen CA dkk, penyunting. Head and neck surgeryotolaryngology Philadelphia Lippincott Williams \& Wilkins Edisi ke-5. 2012;97.

[3] Randal P. Neoplasm of the Nasopharynx. In Ballengers Otorhinolaryngology Head and Neck Surgery. 17 edition. Connecticut: BC Decker Ink. 2009:96;1081-9.

[4] MJR. Nasopharyngeal Carcinoma. Comprehensive Review of Otolaryngology. 2014:Saunders, 197-8.

[5] Ganzer U, Arnold A. Tumours of the Nasopharynx. Otorhinolaryngology, Head and Neck Surgery: Springer; 2010. p. 327-30.

[6] Lee N, Romanyshyn J, Caria N, J. S. Benign \& Malignat lesions of The Ora Cavity, Oropharynx \& Nasopharynx. In Lalwani AK, editors. Current Diagnosis and treatment in otolaryngology-head and neck surgery Third Edition, Lange. 2012:377-86.

[7] Tan K, Putti T. Cyclooxygenase 2 expression in nasopharyngeal carcinoma: immunohistochemical findings and potential implications. Journal of clinical pathology. 2005;58(5):535-8.

[8] Forastiere AA, Ang K, Brizel D, Brockstein BE, Dunphy F, Eisele DW, et al Head and neck cancers: Clinical practice guidelines. JNCCN Journal of the National Comprehensive Cancer Network. 2005;3(3):316-91.

[9] Alavanja M, Allen N, Bartsch H, Bhisey RA, Buffler PA, Chang-Claude J, et al Chinese Style Salted Fish. In: Monographs I, editor. Personal Habits and Indoor Combustions. Lyon: The International Agency for Research on Cancer; 2012. p. 501-10.

[10] Ouyang PY, Su Z, Mao YP, Liang XXX, Liu Q, Xie FY. Prognostic Impact of Family History in Southern Chinese Patients with Undifferentiated Nasopharyngeal Carcinoma. British Journal of Cancer. 2013; 109:788-94.

[11] Tan L, Loh T. Benign and malignant tumors of the nasopharynx. In: Flint P, Haughey BH, Lund V, et al, editors. Cummings Otolaryngology. 6th ed. Philadelpia:Saunder, 2015. p. 1420-31.

[12] Lin H-S, Fee W. Malignant nasopharyngeal tumors. eMedicine journal(Diunduh 25 Desember 2007) Tersedia dari: URL: http://www/emedicine com/ent/topic. 2009;269.

[13] MA J, Cao S. The Epidemiology of Nasopharyngeal Carcinoma. In: Lu JJ, Cooper JS, Lee AW. Nasopharyngeal Cancer. London: Springer. 2010.p.1-7.

[14] Licitra L, Bernier J, Cvitkovic E, Grandi C, Spinazzé S, Bruzzi P, et al. Cancer of the nasopharynx. Critical reviews in oncology/hematology. 2003;45(2):199214.

[15] Fachiroh J, Schouten T, Hariwiyanto B. Molecular diversity of Ebstein barr virus IgG and IgA antibody responses in nasopharyngeal carcinoma: a comparisons of Indonesian, Chinnese and European subject. The Journal of Infectious Disease 2014; $190(1)$ : 53-62. 